\title{
Municipal Foreman Killed When Struck by a Backhoe Loader Outrigger While in an Excavation - Massachusetts
}

Release Date: March 30, 2016

Investigation: \# 14-MA-003-01
Massachusetts Department of Public Health Occupational Health Surveillance Program

\section{SUMMARY}

On February 4, 2014, a 48-year-old male general foreman (victim) employed by a local municipal water department was fatally injured while repairing a water line break. The victim was inside an excavated hole located in a roadway with three other co-workers. A backhoe loader was positioned near the trench with its outriggers extended and bucket attachment resting inside the dump section of a dump truck. The backhoe loader was unintentionally pulled forward when the dump truck was driven forward. As the backhoe loader was pulled forward, the outrigger on the right side struck the victim and dragged him out of the excavated hole. A police officer performing a traffic detail was on site and placed a call for emergency medical services (EMS). EMS, the fire department and the local and state police arrived at the incident location within minutes. The victim was pronounced dead at the scene.

Contributing factors identified in this investigation included resting the backhoe bucket attachment in the dump truck when not being used, lack of communication among workers, not closing the roadway during the repair resulting in a limited work area, and absence of a safety and health program.

The Massachusetts FACE Program concluded that to prevent similar occurrences in the future, employers should:

- Ensure that when excavating equipment is not being used that the equipment is moved away from the excavation edge and all attachments are lowered to the ground before workers enter the excavation;

- Ensure that before moving equipment located on work sites that the operator performs a walk around to warn workers on foot that the equipment will be moved and to identify potential obstacles;

- Consider closing roadways when the work area is located in a roadway and there is limited space for the work area, and multiple large pieces of equipment are needed to complete tasks;

- Develop, implement, and enforce a safety and health program that addresses hazard recognition and control and avoidance of unsafe conditions; and

- Provide work environments for employees that, at a minimum, meet all relevant Occupational Safety and Health Administration (OSHA) regulations and industry accepted standards of practice per the Department of Labor Standards policy. 
On February 5, 2014, the Massachusetts FACE Program was alerted by the local media that on the day before, a male water department employee was fatally injured while repairing a water pipe. On May 28, 2014, the Massachusetts FACE Program Director traveled to the municipal water department's office location and met with the department representative to discuss the incident. The police report, death certificate, and municipal information were reviewed. In addition, the incident location was visited and photographed.

\section{EMPLOYER}

The employer was a municipal department of public works for a Massachusetts town with over 33,000 residents that was incorporated in the late 1700's. The public works department had about 72 employees at the time of the incident, and of these, approximately 50 were water department employees. Most of the city's non-management water department employees had union representation, as did the victim.

\section{WRITTEN SAFETY PROGRAMS AND TRAINING}

At the time of the incident, the department did not have a safety and health program. Workers were provided basic training and were also provided with personal protective equipment (PPE), including hearing and eye protection and high visibility safety apparel. At the time of the incident, the highvisibility safety vests being used were American National Standards Institute's (ANSI) Class 2 compliant, but the department had already switched to Class 3 vests at the time of the site visit. All department employees, including the victim, held Commercial Drivers Licenses.

\section{VICTIM}

The victim was a 48-year-old male who had been employed with the municipal department of public works for 26 years at the time of the incident. He started with the town as a laborer and had advanced to the job title of general foreman by the time of the incident. He held a current state-issued Class 2 hoisting engineer license, which is for operating excavating equipment, from the Massachusetts Department of Public Safety.

The day of the incident, a Tuesday, the victim arrived at the department's office/garage location at approximately 7:00 a.m. He was scheduled to work a normal 8-hour shift, when a call came in for a water line break at the end of his shift. At around 4:00 p.m., the victim and five other water department employees left the department garage to go to the location of the reported water line break.

\section{INCIDENT LOCATION}

The incident occurred in a suburban area that was mostly made up of a residential neighborhood with single family homes, municipal playing fields and a golf course (Figure 1). The roadway where the incident occurred was an asphalt roadway that primarily ran north and south. The roadway had two travel lanes, one for each direction. The travel lanes were approximately 12 feet wide each and were separated by painted solid double yellow lines. The outer edges of the lanes had painted solid white fog lines followed by a two foot wide paved shoulder and then granite curbing. The east side of the northbound travel lane had a paved sidewalk and the west side of the southbound travel lane had a grass sidewalk. Both sidewalks were about six feet wide. The posted speed limit for this street was 30 miles per hour. The roadway was relatively straight and flat in this area.

The incident occurred at a T-shaped intersection with a residential side street that intersected the main roadway from the east (Figure 2). The side street was asphalt, had one lane for both directions of travel 
and no roadway marking except at the intersection with the main roadway. At the intersection there was a painted crosswalk across the side street and a white painted stop line, but no stop sign. The area beyond the west side of the T-shaped intersection was vegetation that abutted the golf course property.

\section{EQUIPMENT}

The machine involved in the incident was a backhoe loader that was purchased new by the town in 2008. One end had a loader attachment and the other end of the machine had a backhoe attachment (Figure 3). There were two outriggers (stabilizers) at the end where the backhoe attachment was located. The backhoe loader's dimensions were 9.3 feet high to the top of the cab, 7.7 feet wide with outriggers stowed, and 13.3 feet wide with the outriggers extended. The backhoe loader had an operating weight of about 15,000 pounds.

The dump truck involved in the incident was purchased new by the town in 2000. The truck's chassis had six wheels and two axles, with dual wheels in the rear and a hydraulic dump body. There was also a town owned vacuum truck on site at the time of the incident. The vacuum truck was being used to control the amount of water accumulating in the excavation.

\section{INVESTIGATION}

On the day of the incident, a call came in to the water department office after 3:00 p.m. that there was a water pipe break. The victim and five co-workers were assigned to repair the water pipe break. The work crew included a general foreman (victim), working foreman, laborer, and heavy equipment operators. The work crew left the water department garage around 4:00 p.m. to travel to the location of the break, the T-shaped intersection. It was estimated that the repair would take four hours to complete. At the time of the incident, it was dark, there was no wind and the temperature was about 28 degrees Fahrenheit. A storm was forecasted for the following day and the prediction was nine inches of snow fall.

The work crew arrived at the work site location with the backhoe loader, dump truck, and a vacuum truck (Figure 4). They also brought a light tower to illuminate the work area, due to it being dark outside. The work crew estimated the break location and excavated a hole that was approximately ten feet long by six feet wide and five feet deep to locate the break. The excavated hole was located in the T-shaped intersection southbound travel lane, directly across from the side street. The backhoe section of the backhoe loader was used to excavate the hole and was positioned in the southbound travel lane just north of the hole. The backhoe loader's outriggers were in use and extended while digging the excavation and at the time of the incident. The dump truck was positioned next to and immediately east of the hole. This position placed the dump truck over the painted solid double yellow line and partially in the northbound travel lane. The light tower was located to the west of the hole. The vacuum truck was positioned in the southbound travel lane just south of the hole to control the water level in the excavation. The northbound travel lane was kept open during the repair process and a town police officer was on site with a police car conducting traffic control as part of a traffic detail.

The dump truck was on site to contain the spoil pile; the soil excavated from the hole was placed in the dump truck's dump bed. Once the excavation was completed, the backhoe loader's backhoe bucket attachment was placed inside the dump truck's dump bed and the backhoe loader operator remained inside the cab. Then four water department employees, including the victim, climbed into the excavation to find the leak. They discovered that a one-inch plug had let go, causing the leak. The four workers started to conduct the repair to the pipe. Due to the cramped working area around the excavated hole, 
the dump truck was parked close to the excavation edge. It was reported by water department personnel that the working foreman asked that the dump truck be moved because it was in the way and there was concern it was parked too close to the excavation edge. At approximately 7:15 p.m., the working foreman told the dump truck operator to quickly move the dump truck. The driver immediately climbed into the dump truck cab to move the truck forward in a southerly, direction. Due to the location of the vacuum truck, the dump truck, once moving, was going to have to be driven forward and to the left (east) to get around the front edge of the vacuum truck.

It appears that when the dump truck operator attempted to drive the truck forward, the truck did not move, resulting in the operator trying to accelerate more. Once the dump truck started to move forward, the backhoe loader was dragged with the dump truck due to the backhoe attachment being located inside the dump truck bed. As the backhoe loader was pulled in the forward direction (south), its outrigger that was extended to the west moved across the top of the excavation, striking the victim and one of the coworkers. The victim was then caught on the outrigger and was dragged up and out of the excavated hole and onto the roadway while the co-worker remained in the excavation. The backhoe loader continued to move forward, as the victim laid on the roadway between the excavated hole and the vacuum truck. Then the backhoe loader's extended outrigger struck and got caught on the right front tire of the vacuum truck and started to drag the vacuum truck. The vacuum truck was dragged approximately 4 feet to the south before the backhoe loader disengaged from the dump truck. The dump truck continued forward and then came to a stop about 240 feet from its starting location. The backhoe loader had been dragged approximately 38 feet while the operator was inside the cab.

The police officer at the incident location performing the traffic detail immediately placed calls for emergency medical services (EMS) and started cardiopulmonary resuscitation (CPR). EMS, state and additional local police arrived at the incident location within minutes. The victim was pronounced dead at the incident location. The co-worker was transported to a local hospital and was released days later.

\section{CONTRIBUTING FACTORS}

Occupational injuries and fatalities are often the result of one or more contributing factors or key events in a larger sequence of events that ultimately result in the injury or fatality. The Massachusetts FACE team identified the following contributing factors in this incident.

- Resting the backhoe bucket in the dump of the dump truck

- Lack of communication among workers

- Not closing the roadway during the repair resulting in a limited work area

- Absence of a safety and health program

\section{CAUSE OF DEATH}

The medical examiner listed the cause of death as multiple blunt force injuries of head and torso. 


\section{RECOMMENDATIONS/DISCUSSION}

\section{Recommendation \#1: Municipalities should ensure that when excavating equipment is not being used that the equipment is moved away from the excavation edge and all attachments are lowered to the ground before workers enter the excavation.}

Discussion: At the time of the incident, the hole had been dug and the backhoe was not going to be used again until it was time to fill in the excavated hole after the repair was complete. During the repair, the dump truck remained at the excavation edge along with the backhoe, and the backhoe's attachment was in a raised position and resting inside the dump truck bed. It was suggested during the investigation that the backhoe attachment could have been placed inside the dump truck's bed due to the limited space around the work area.

The hub of activity at work sites with excavations is typically around the location of the excavation itself. To help ensure the safety of workers on excavation sites, always move equipment that is not in use away from the excavation edge and lower all equipment attachments to the ground, even if the operator is going to exit the cab for only a short period of time. ${ }^{1}$ In this case, if equipment was moved and attachments were lowered before workers were allowed to enter the excavation, the incident would not have occurred.

\section{Recommendation \#2: Municipalities should ensure that before moving equipment located on work sites that the operator performs a walk around to warn workers on foot that the equipment will be moved and to identify potential obstacles.}

Discussion: It is well documented that it can be difficult for operators seated in a cab of most large dump trucks and other large mobile equipment to see all the way around the vehicle due to blind spots. Blind spots are the areas around a vehicle or piece of mobile equipment that is not visible to the operator, either by direct line-of-sight or indirectly by the use of internal and external mirrors. Blind spots may exist all around equipment due to the configuration of the operator cab, attachments, truck beds, and mirrors. ${ }^{2}$ To help ensure safe movement of equipment located on work sites, equipment operators should perform a walk around of any equipment they are going to move, immediately prior to moving the equipment, to identify obstacles and warn other workers. Training about blind spots is important for both operators and workers on foot in proximity to mobile vehicles and equipment.

Just prior to the incident, the dump truck driver was outside of the truck's cab when the foreman asked that the dump truck be moved away from the excavation edge. It appears that there was some concern about how close the dump truck was parked to the excavation's edge. The dump truck operator quickly climbed into the cab of the dump truck and started to drive the truck forward, pulling the backhoe with the truck.

In this case, if the dump truck operator had performed a walk around the truck he would have observed the backhoe attachment that was resting inside the truck's bed and had the backhoe loader operator move the attachment and lower it to the ground. Performing a walk around before moving large equipment will also increase communication among workers that will help create a safer work site. When workers are aware of the tasks that their co-workers are going to be starting, this will help ensure the safety of the work site. 


\section{Recommendation \#3: Municipalities should consider closing roadways when the work area is located in a roadway and there is limited space for the work area, and multiple large pieces of equipment are needed to complete tasks.}

Discussion: During the repair, the water department had kept the northbound lane of the roadway open to traffic at the incident location. Keeping the roadway open to traffic created a small work area and resulted in the dump truck and backhoe being positioned at the excavation edge. When a work site is going to be located in or close to a roadway, prior to beginning work, a plan should be developed about how to complete the task and where equipment will be positioned. Serious consideration should be given to the possibility of closing the roadway when it increases the safety of the workers or the public.

In this case, taking into consideration the location and the time of day, the section of roadway where the repair was going to take place could have been closed to traffic without major impact to the general public. The roadway closure could have been from the side street at the incident location north to the municipal public works department, and access to these locations could have been maintained. The one area that the public would not have had access to was the municipal playing fields, which were not being used due to the time of year. Closing the roadway would have provided the space needed to create a larger work site where equipment could have been easily located away from the excavation when not in use.

Whenever work is being performed in or along a roadway and it will involve altering motor vehicle traffic, there are federal procedures that should be followed to ensure the safety of both the workers on foot and the general public. This type of worksite is referred to as a work zone. ${ }^{3}$ The U.S. Department of Transportation's (DOT) Manual on Uniform Traffic Control Devices (MUTCD) sets forth the basic principles that govern the design and usage of traffic control signs and devices. ${ }^{4}$ Part 6 of the MUTCD provides specific work zone designs to be used during roadway construction, maintenance, and utility operations. To help ensure employee safety while performing these and other roadway operations, employers should follow the MUTCD minimum standards and guidelines in Part 6. These standards and guidelines will help determine the appropriate number and location of traffic control devices, such as warning signs, cones, and lights.

\section{Recommendation \#4: Employers should develop, implement, and enforce a safety and health program that addresses hazard recognition and control and avoidance of unsafe conditions.}

Discussion: A safety and health program should include the systematic identification, evaluation and prevention or control of general workplace hazards and the hazards of specific jobs and tasks. The major elements of an effective program are management leadership, worker participation, hazard identification and assessment, hazard prevention and control, education and training, and program evaluation and improvement. ${ }^{5,6}$ The program should also include an explanation of the worker's rights to protection in the workplace, safe work practices workers are expected to adhere to, specific safety protection for all tasks workers perform, how workers can identify and avoid hazards, and who workers should contact when safety and health issues or questions arise.

In this case, procedures as part of the safety and health program should be developed for job sites that will involve excavations, mobile equipment, and workers on foot working within one location to complete tasks. Procedures should include conducting a job hazard analysis (JHA) to evaluate the work site before work begins. ${ }^{7}$ A JHA will help to determine the best locations for equipment, machinery, 
tools and workers, personal protective equipment (PPE) workers will need to complete tasks and other hazards that might be encountered while completing the tasks. These procedures could also include guidance about when roadways could be closed to traffic.

When developing a safety and health program, employers should start by evaluating all tasks performed by employees to identify potential hazards and incorporate information about these hazards into the program. When determining potential hazards associated with equipment, the manufacturer operator's manual and the equipment's warning decals should be reviewed. Employers should also use their employees' expertise throughout the program development process by seeking employee input. Once hazards have been identified information on their controls should be added into the program. ${ }^{5}$ The safety and health program should outline requirements for performing a hazard analysis of any new process that includes new equipment, products and chemicals, and any situation where new hazards have the potential to arise. Also, the program should routinely be updated when safety concerns arise and when new equipment and new tasks are introduced into the workplace.

Once the safety and health program has been developed, employers should ensure that they have fully and effectively implemented their program by routinely performing assessments of tasks and immediately addressing any observed unsafe conditions. Training should be provided to all employees on the program's topics, and procedures, and should also include hazard recognition and the avoidance of unsafe conditions. All training provided to employees should be documented. When the program is updated, employers should then provide additional training on the new and updated safety and health program topics.

The Massachusetts Department of Labor Standards (DLS) offers free consultation services to help small employers improve their safety and health programs, identify hazards, and train employees. DLS can be contacted at 978-242-1351. More information about DLS can be found on their Web site at www.mass.gov/dos/consult.

The Massachusetts Department of Industrial Accidents (DIA) has grants available for providing workplace health and safety training to employers and employees. Any company covered by the Massachusetts Workers' Compensation Insurance Law is eligible to apply for these grants. More information about these DIA grants can be found on their Web site at www.mass.gov/dia/safety.

\section{Recommendation \#5: Municipalities should provide work environments for employees that, at a minimum, meet all relevant Occupational Safety and Health Administration (OSHA) regulations and industry accepted standards of practice per the Department of Labor Standards policy.}

Discussion: The federal Occupational Safety and Health Act require private sector employers to provide workplaces that are free from recognized hazards likely to cause death or serious physical harm to employees. While private sector employees are covered by federal OSHA, public sector employees in Massachusetts are not. In accordance with Massachusetts General Law Chapter 149 Section 61/2, Massachusetts executive branch state agencies must comply with OSHA regulations to protect state workers. This is enforced by the Massachusetts Department of Labor Standards.

In this case, the incident involved a municipal public sector workplace. The Massachusetts Department of Labor Standards (DLS), in accordance with Chapter 149 Section 6, is charged with inspecting municipal workplaces and determining what procedures and practices are required to protect municipal 
workers. ${ }^{8}$ As a matter of policy, DLS references OSHA regulations, standards set forth in the MUTCD, as well as other consensus standards such as those developed by the American National Standards Institute (ANSI), in determining whether proper procedures are being followed to protect municipal workers. In this case, adhering to the following OSHA standard may have prevented this incident: 29 CFR 1926.600, Equipment. This standard includes heavy equipment attachments to be fully lowered when not in use.

DLS has enhanced efforts to improve health and safety conditions for municipal workers by increasing incident inspections and voluntary technical assistance for municipalities. During an incident inspection if conditions are observed that could cause worker injury or illness, a written warning will be issued by DLS with an order to correct the identified hazards. If the identified hazards are not corrected within the timeframe specified in the written warning, then monetary civil penalties may be issued by DLS to the employer.

\section{REFERENCES}

1. Code of Federal Regulations. 29 CFR 1926.600 Equipment. Washington DC. U.S. Government Printing Office, Office of the Federal Register.

2. NIOSH 2009. Workplace Safety and Health Topics: Construction Equipment Visibility. www.cdc.gov/niosh/topics/highwayworkzones/BAD/imagelookup.html. Date accessed: October 6, 2015.

3. NIOSH 2009. Workplace Safety and Health Topics: Highway Work Zone Safety. www.cdc.gov/niosh/topics/highwayworkzones/. Date accessed: October 6, 2015.

4. U.S. DOT 2009. Manual on Uniform Traffic Control Devices (MUTCD), 2009 Edition, U.S. Department of Transportation Federal Highway Administration. http://mutcd.fhwa.dot.gov/. Date accessed: October 2, 2015.

5. OSHA. Safety and Health Program Management Systems eTool.

www.osha.gov/SLTC/etools/safetyhealth/index.html. Date accessed: September 14, 2015.

6. Code of Federal Regulations. 29 CFR 1910.332 Training. Washington DC. U.S. Government Printing Office, Office of the Federal Register.

7. OSHA 2002. Job Hazard Analysis, Publication No. 3071.

www.osha.gov/Publications/osha3071.pdf. September 14, 2015.

8. Massachusetts General Laws, Chapter 149: Section 6. Safety devices and means to prevent accidents and diseases generally; fees for structural painting. 
Figure 1 - Aerial view of the T-shaped intersection where the incident occurred

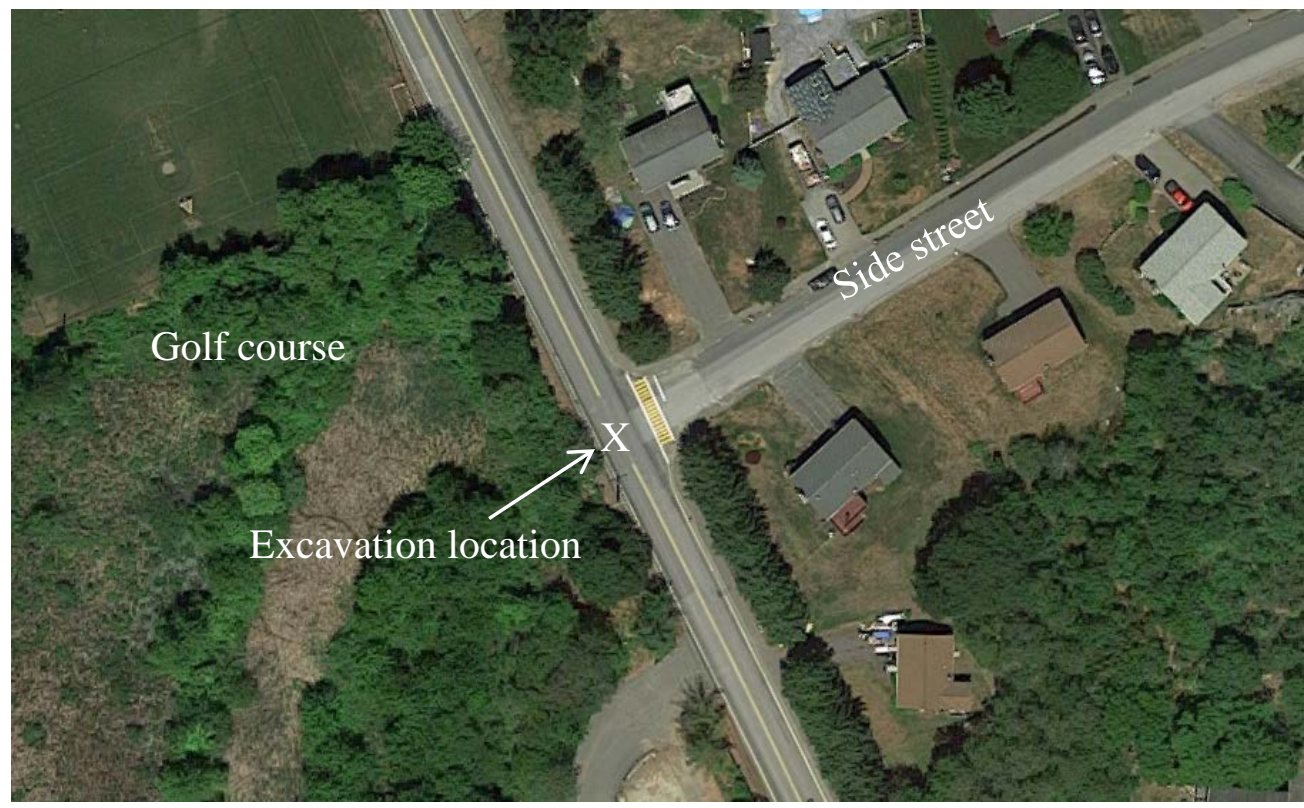

Figure 2 - Roadway view of the T-shaped intersection with excavation location outlined

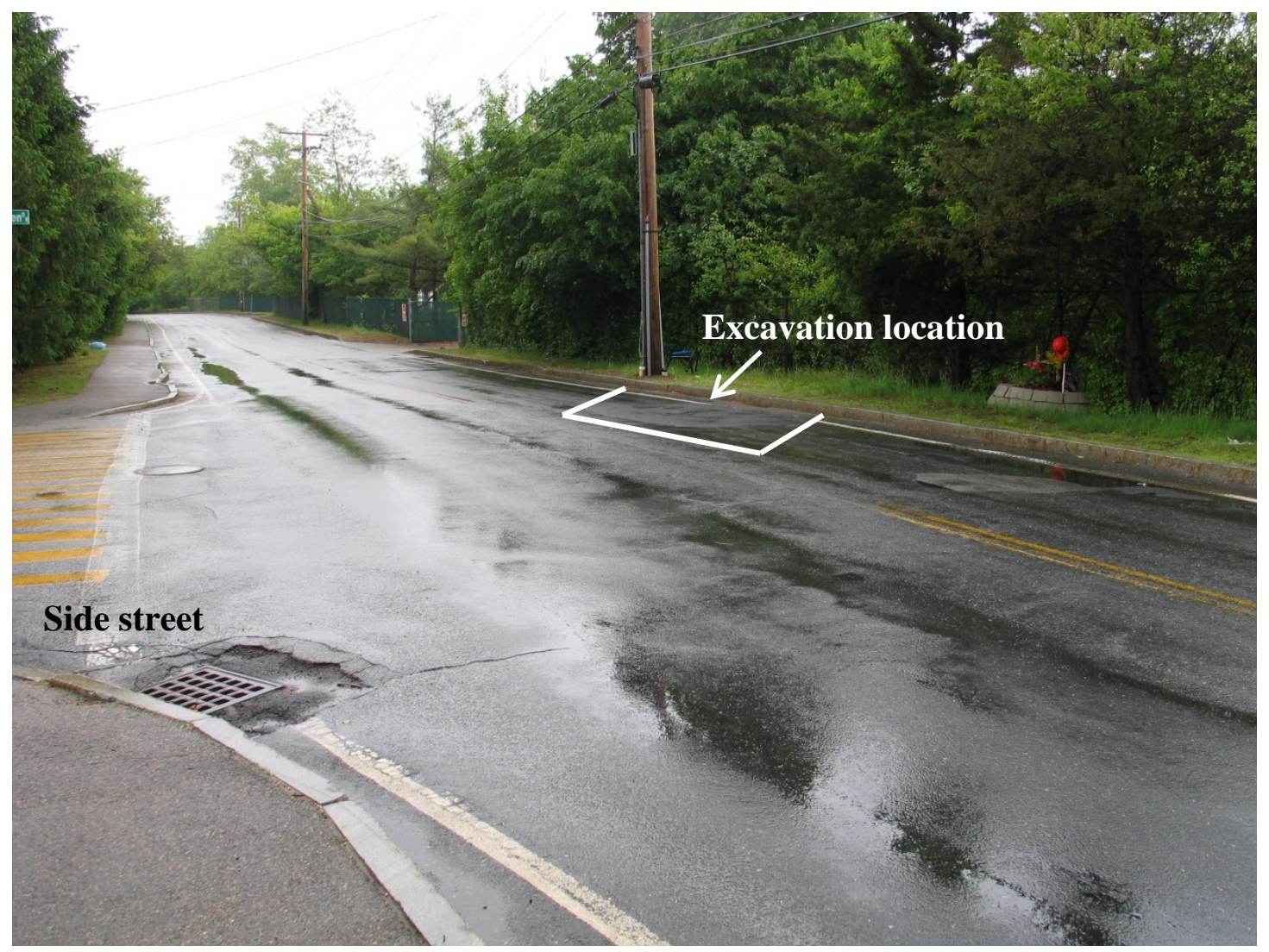


Figure 3 - Backhoe similar to the one involved in the incident

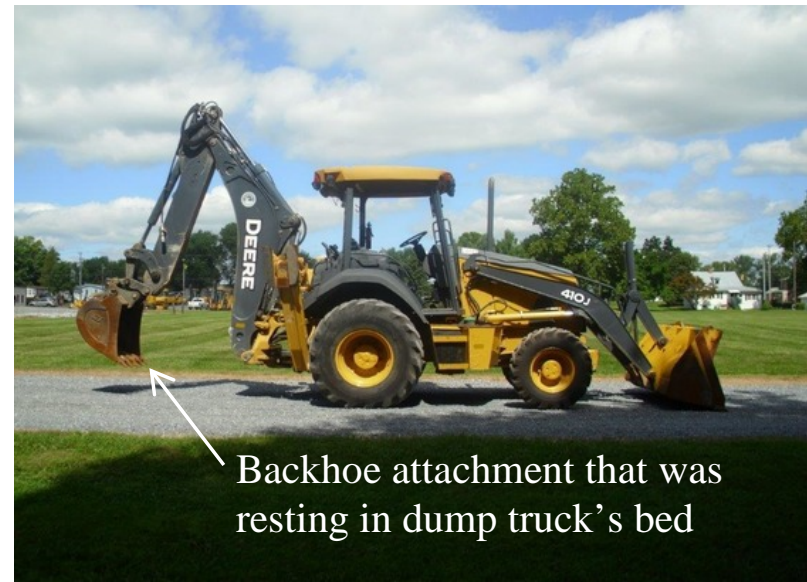

Figure 4 - Roadway view of the T-shaped intersection with outline of vehicles and excavation location

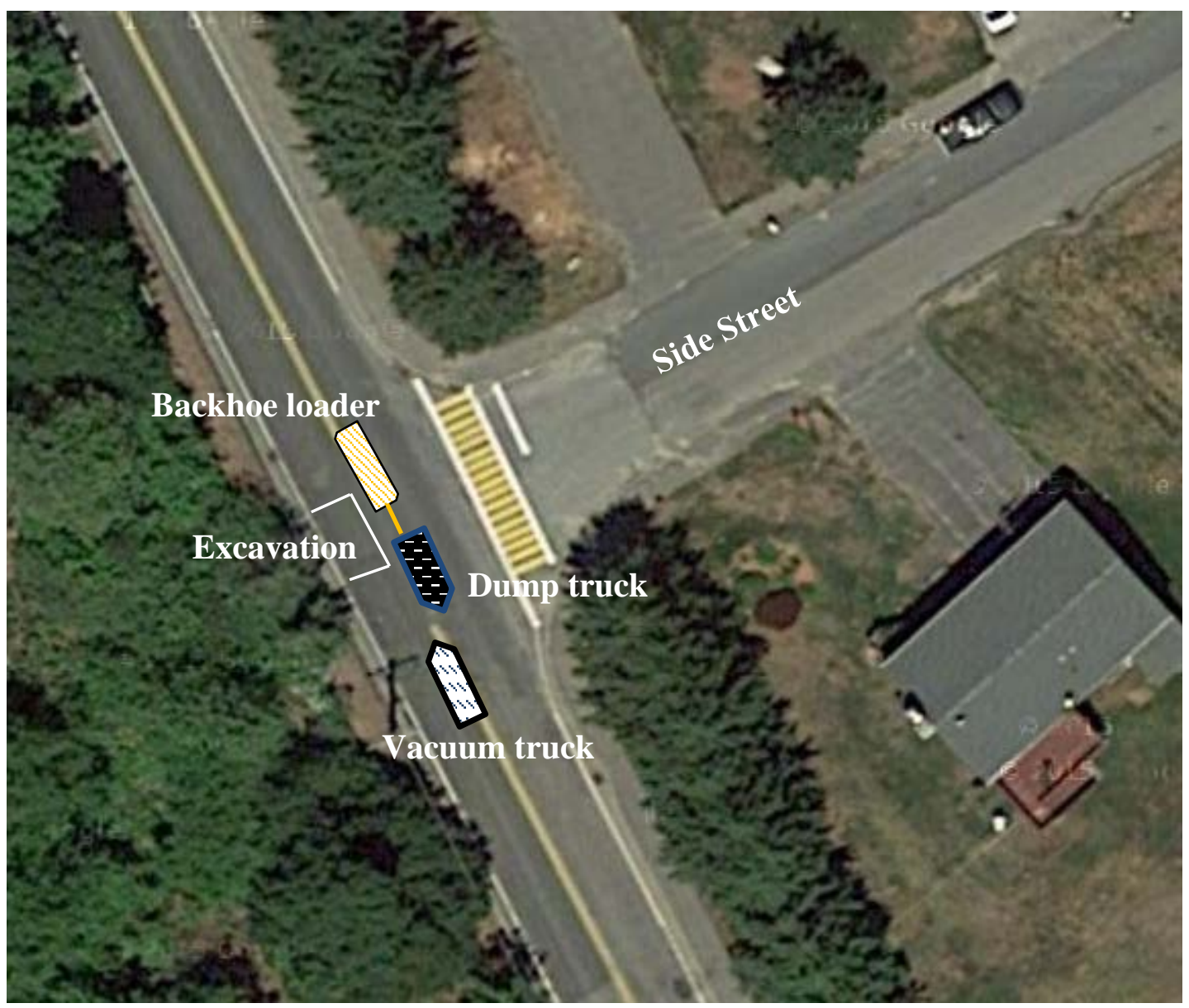


Michael A. Fiore, MS, Director Massachusetts FACE Program Occupational Health Surveillance Program Massachusetts Department of Public Health
Letitia Davis, Sc.D., Ed.M., Director

Occupational Health Surveillance Program

Massachusetts Department of Public Health

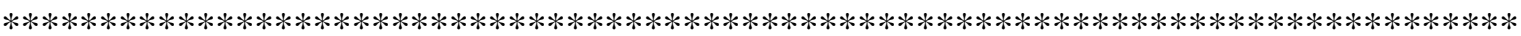

\section{FATALITY ASSESSMENT AND CONTROL EVALUATION PROGRAM}

The Massachusetts Department of Public Health, in cooperation with the National Institute for Occupational Safety and Health (NIOSH), conducts investigations on the causes of work-related fatalities. The goal of this program, known as Massachusetts Fatality Assessment and Control Evaluation (Massachusetts FACE) is to prevent future fatal workplace injuries. Massachusetts FACE aims to achieve this goal by identifying and studying the risk factors that contribute to workplace fatalities, by recommending intervention strategies, and by disseminating prevention information to employers and employees.

Massachusetts FACE also collaborates with engineering and work environment faculty at the University of Massachusetts at Lowell to identify technological solutions to the hazards associated with workplace fatalities.

NIOSH funded state-based FACE Programs currently include: California, Kentucky, Massachusetts, Michigan, New York, Oregon, and Washington.

Additional information regarding this report is available from:

Occupational Health Surveillance Program

Massachusetts Department of Public Health

250 Washington Street, 4th floor

Boston, Massachusetts 02108-4619

(617) 624-5627

\section{Evaluate this report}

We would appreciate your feedback on these reports so we may continue to improve the MA FACE project and our investigation reports. A feedback form can be found at:

www.mass.gov/eohhs/docs/dph/occupational-health/report-evaluation.doc

The completed form may be returned by fax to (617) 624-5676, by mail to FACE, 250 Washington Street, $4^{\text {th }}$ Floor, Boston, MA 02108, or by email to ma.face@state.ma.us. 